\title{
Transient Response of a Tall Object to Lightning
}

\author{
Vladimir A. Rakov
}

\begin{abstract}
Experimental data showing the transient behavior of tall objects struck by lightning are reviewed. The influence of this transient behavior, illustrated by simple calculations, on measured lightning current and measured remote electromagnetic fields is discussed. The estimated equivalent impedance of the lightning channel at the time of the initial current peak is appreciably higher than the characteristic impedance of an ordinary tall object (a factor of 3 or so for both the Ostankino and Peissenberg towers and about a factor of 2 for the $\mathrm{CN}$ tower). The grounding impedance of a tower is typically lower than its characteristic impedance. Thus, the current reflection coefficient is negative at the top and positive at the bottom of the tower. The similarity of the statistical distributions of subsequent-return-stroke peak currents in: 1) natural downward lightning; 2) natural upward (object-initiated) lightning; and 3) rocket-triggered lightning measured at objects with heights ranging from 4.5 to $540 \mathrm{~m}$ suggests that current peaks are not significantly influenced by the presence of a tall object, provided that measurements are taken at the top of the object. This inference is consistent with modeling results of Melander who showed that the current peaks measured in Switzerland and Italy at the top of 70-m and 40-m towers, respectively, are essentially unaffected by the presence of the towers. If lightning current could be represented by an ideal current source, current at the top of the object would be equal to the source current at all times. The peak current measured at the bottom of a tall object is usually more strongly influenced by the transient process in the object than the peak current at the top. For example, peak currents measured in the lower part of the 540-m Ostankino tower are about a factor of two higher than the peak currents measured near the tower top because the current reflection coefficient at the bottom of the tower is near +1 . Observations and modeling suggest that a tall metallic strike object replacing the lower part of lightning channel serves to enhance the lightning-radiated electromagnetic fields relative to the fields due to similar lightning discharges attached directly to ground, this effect being more pronounced for the sharper lightning current pulses.
\end{abstract}

Index Terms-Lightning, lightning current, lightning electromagnetic field, tall objects, transients, traveling waves.

\section{INTRODUCTION}

$\mathbf{T}$ HE lightning return-stroke current frequency spectrum extends from near d.c. to tens of megahertz. Thus, a lightning current waveform can be viewed as being the superposition of a large (strictly speaking infinite) number of frequency components each having wavelength $\lambda=c f^{-1}$ where $c$ is the speed of light in free space, and $f$ is the frequency in hertz. If the height of a strike object is comparable to or greater than some of these wavelengths, usually the shortest wavelengths which

Manuscript received May 30, 2000; revised July 25, 2001. This research was supported in part by the National Science Foundation under Grant ATM-9 726100 and Grant ATM-0 003994.

The author is with the Department of Electrical and Computer Engineering, University of Florida, Gainesville, FL 32611-6130 USA.

Publisher Item Identifier S 0018-9375(01)10229-2.
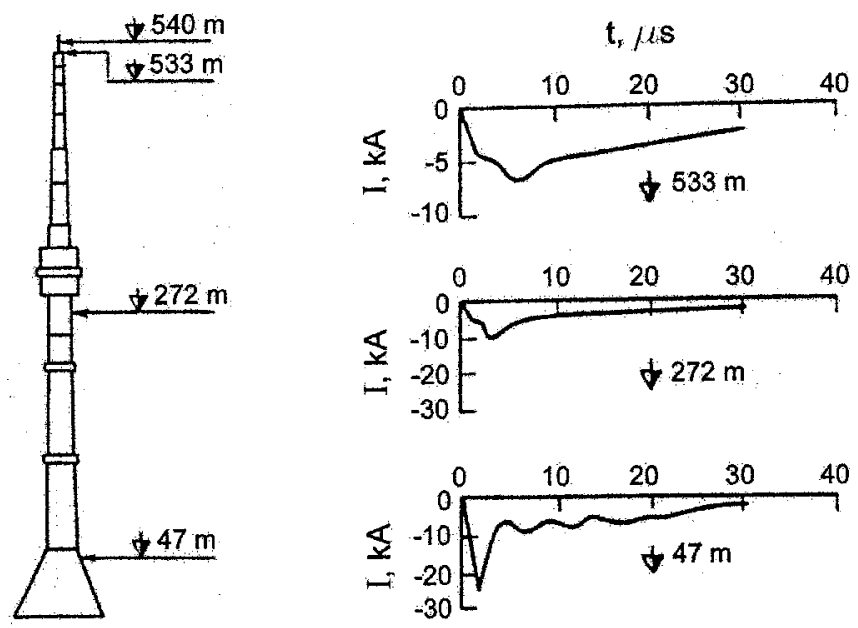

Fig. 1. Typical return-stroke current waveforms of upward negative lightning recorded near the top (at $533 \mathrm{~m}$ ), in the middle (at $272 \mathrm{~m}$ ), and near the bottom (at $47 \mathrm{~m}$ ) of the 540-m high Ostankino tower in Moscow. Differences in current waveforms at different heights are indicative of the tower behaving as a distributed circuit. Adapted from Gorin and Shkilev [16].

are associated with the initial rising portion of the lightning return stroke waveform, the object behaves (at the corresponding frequencies) as a distributed circuit, as opposed to a lumped circuit. As a result, impulsive lightning currents measured on such "electrically long" objects can be influenced ("contaminated") by the transient process occurring in the object. In Sections II A and II B, experimental data that are indicative of transient processes in tall towers are reviewed. Some researchers (e.g., Guerrieri et al. 1998 [5]) alleged that the statistics on lightning return stroke current parameters based on measurements on tall towers may be not representative of lightning discharges to ground in the absence of the tall object due to current reflections from the bottom and top of the object. The estimation of this potential bias is important, since direct current measurements for natural lightning are usually performed on relatively tall instrumented towers. In Section III, we will try to estimate the magnitude of such bias. Most important, we will show that tower-top current measurements on Mount San Salvatore in Switzerland (Berger et al. 1975 [1]), that are usually viewed as the primary reference source for lightning research, EMC analyses, and lightning protection practice, are not significantly affected by the transient response of the 70-m high towers. Finally, in Section IV, we consider electromagnetic fields due to lightning strikes to tall objects. A detailed review of the literature on the computation of lightning fields using various return-stroke models extended to include the strike object (Diendorfer and Uman 1990 [2]; Zundl 1994a [3]; Guerrieri et al. 1996, 1998, 2000 [4]-[6]; Rusan et al. 1996 [7]; Motoyama et al. 1996 [8]; Rachidi et al. 1998 [9]; Janischewskyj et al. 1998, 1999a [10], [11]; Shostak 
TABLE I

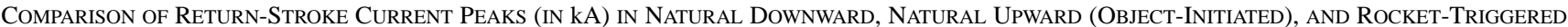
LightNing EFFECTIVELY TRANSPORTING NEGATIVE CHARgE TO GROUND

\begin{tabular}{|c|c|c|c|c|c|c|c|c|c|}
\hline \multirow{2}{*}{ Reference } & \multirow{2}{*}{$\begin{array}{c}\text { Object } \\
\text { Height, } m\end{array}$} & \multirow{2}{*}{ Location } & \multirow{2}{*}{ Sample Size } & \multicolumn{6}{|c|}{ Percent Exceeding Tabulated Value } \\
\hline & & & & $99 \%$ & $95 \%$ & $90 \%$ & $50 \%$ & $10 \%$ & $5 \%$ \\
\hline \multicolumn{10}{|l|}{ Subsequent return-strokes in natural downward flashes } \\
\hline Anderson and Eriksson (1980) [36] & 70 & Switzerland & 114 & - & 4.9 & - & 12 & - & 29 \\
\hline Return strokes in object-initiated flashes & & & & \multicolumn{6}{|c|}{. } \\
\hline Fuchs et al. (1998) [37] & 160 & Germany & $\begin{array}{c}35 \\
\text { ( } \beta \text { components) }\end{array}$ & 2.7 & - & - & 8.5 & - & 20 \\
\hline \multirow[t]{2}{*}{ Gorin and Shkilev (1984) [16] } & 540 & Russia & $\begin{array}{c}58 \\
\text { (measurements at } \\
533 \mathrm{~m} \text { above } \\
\text { ground) }\end{array}$ & $\cdot$ & - & 4 & 9 & 19 & - \\
\hline & & & $\begin{array}{l}76 \\
\text { (measurements at } \\
47 \mathrm{~m} \text { above } \\
\text { ground) }\end{array}$ & - & - & $4^{2}$ & $18^{\mathrm{a}}$ & $40^{\mathrm{a}}$ & $\cdot$ \\
\hline Berger (1978) [38] & 70 & Switzerland & 176 & - & - & 4.2 & 10 & 25 & - \\
\hline Hagenguth and Anderson (1952) [39] & 410 & New York & $84^{\mathrm{b}}$ & - & 4 & 5 & 10 & 27 & 35 \\
\hline \multicolumn{10}{|l|}{ Return strokes in rocket-triggered flashes } \\
\hline Fisher et al. (1993) [40] & $\$ 7.8$ & $\begin{array}{c}\text { Florida } \\
\text { (KSC) and } \\
\text { Alabama }\end{array}$ & 45 & - & 4.7 & - & 13 & - & 29 \\
\hline \multirow[t]{2}{*}{ Depasse (1994) [41] } & $5.8-20$ & Florida (KSC) & 305 & - & 4.7 & - & 12 & - & 31 \\
\hline & $\sim 5-20$ & France & 54 & - & 4.5 & - & 9.8 & $\cdot$ & 22 \\
\hline
\end{tabular}

${ }^{\circ}$ Overestimates due to a transient process in the tower (see Fig. 1).

${ }^{\mathrm{b}}$ Two events out of 84 were of positive polarity.

et al. 1999a, 2000 [12], [13]; Goshima et al. 2000 [14]; Baba and Ishii (2001) [42]) is beyond the scope of this study. Some of these modeling efforts are reviewed by Rakov and Uman [ 15 , pp. 418-420].

The definition of a lightning current that is not disturbed by the presence of a strike object has important implications for modeling. In this paper, the "undisturbed" current is defined as the short-circuit current, that is, the current that: 1) would be measured at a well-grounded object of negligible height; and 2) could be used in building a Norton equivalent circuit of the source for modeling direct lightning strikes to various objects and systems.

\section{ObServations of Traveling WaVes Within the Tall STRIKE OBJECT}

\section{A. Current Waveforms}

Gorin and Shkilev [16] observed very different lightning current waveforms at heights of 47,272, and $533 \mathrm{~m}$ above ground on the 540-m high Ostankino tower in Moscow (see Fig. 1). The median peak currents from their measurements at 47 and 533 $\mathrm{m}$ were 18 and $9 \mathrm{kA}$, respectively (see Table I). The observed difference in peak current suggests that the effective grounding impedance of the tower is much smaller than its characteristic impedance and that the latter impedance is appreciably lower than the equivalent impedance of lightning channel, as discussed next. Gorin and Shkilev [16] used current oscillograms recorded near the tower top (at $533 \mathrm{~m}$ ), for the cases when current risetime was smaller than the time (about $3.5 \mu \mathrm{s}$ ) required for a current wave to travel (at the speed of light) from the tower top to its foot and back, to estimate the equivalent impedance of the lightning channel. Their estimates varied from $600 \Omega$ to $2.5 \mathrm{k} \Omega$, while the characteristic impedance of the tower was assumed to be $300 \Omega$, and the grounding resistance was assumed to be zero (the low-current, low-frequency value was about $0.2 \Omega$; Gorin et al. 1977) [17].

Beierl [18], from his analysis of current waveforms measured near the top of the 160-m high Peissenberg tower near Munich, Germany, estimated the current reflection coefficient at the bottom of the tower to be about 1 and at the top of the tower about -0.5 . The latter implies that the equivalent impedance of lightning channel is a factor of 3 or so larger than the characteristic impedance of the tower, consistent with the findings of Gorin and Shkilev [16] for the Ostankino tower. Current waveforms measured on the Peissenberg tower (together with fields $200 \mathrm{~m}$ from the tower and with current and field derivatives) are shown in Fig. 2. Fuchs [43] from 13 simultaneous current measurements at the top and bottom of the Peissenberg tower, found that the average current reflection coefficients at the bottom and top of the tower were 0.70 and -0.53 , respectively. The range of variation was from 0.64 to 0.81 at the tower bottom, and it was from -0.39 to -0.68 at the tower top. The average ratio of the equivalent impedance of the lightning channel and the characteristic impedance of the tower was 3.3. Interestingly, Fuchs [43, 

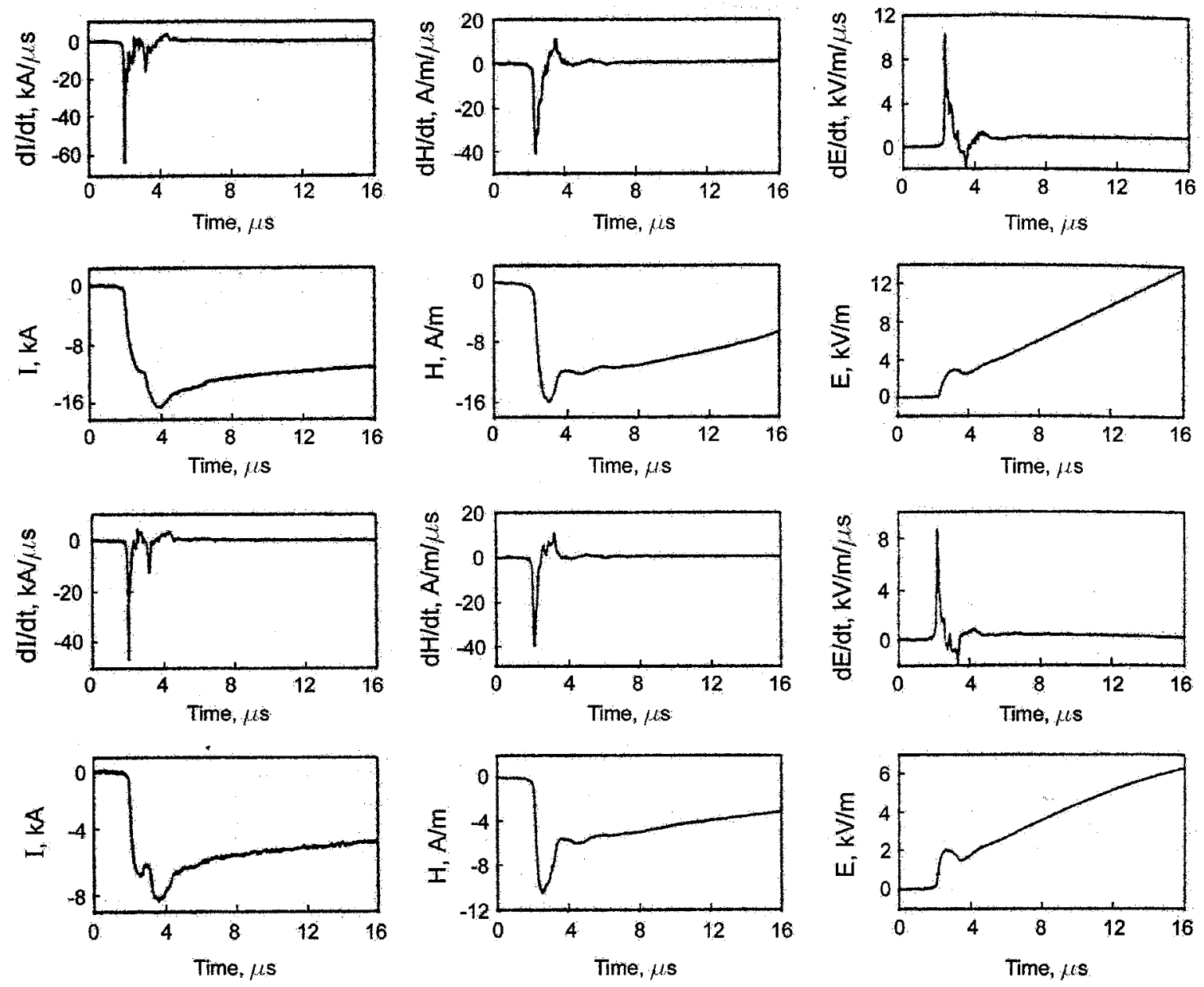

Fig. 2. Current derivative, $d I / d t$, current, $I$, magnetic field derivative, $d H / d t$, magnetic field, $H$, electric field derivative, $d E / d t$, and electric field, $E$, waveforms for the two return strokes in an upward negative flash initiated from the Peissenberg tower on July 19, 1993. The $d I / d t$ and $I$ waveforms were measured at the tower top, and $d H / d t$ and $d E / d t$ waveforms were measured about $200 \mathrm{~m}$ from the tower. The $H$ and $E$ waveforms were obtained by numerical integration of $d H / d t$ and $d E / d t$ waveforms and, therefore, may be distorted after some microseconds. Adapted from Zundl [35].

Figs. 10 and 11] found that the current reflection coefficients at the bottom and at the top of the Peissenberg tower estimated for 11 lightning strokes were apparently independent of either lightning current peak (ranging from about 1 to $8 \mathrm{kA}$ ) or maximum current rate of rise (ranging from about 5 to $60 \mathrm{kA} \mu \mathrm{s}^{-1}$ ).

Janischewskyj et al. [19], from their analysis of 5 current waveforms measured $474 \mathrm{~m}$ above ground on the 553-m high Canadian National $(\mathrm{CN})$ tower in Toronto and modeling, inferred average current reflection coefficients at the bottom and at the top of the tower of about 0.40 and -0.37 , respectively. The reflection coefficient at the tower bottom varied from 0.34 to 0.43 , while the reflection coefficient at the top varied from -0.27 to -0.49 . The average ratio of the equivalent impedance of the lightning channel and the characteristic impedance of the $\mathrm{CN}$ tower was 2.2. The reflection coefficients reported by Janischewskyj et al. [19] were estimated assuming that the $\mathrm{CN}$ tower could be represented by a uniform lossless transmission line. Rusan et al. [7] considered CN tower models composed of 1 to 3 sections of lossless transmission lines with different parameters. It appears from their analysis that inclusion of reflections from discontinuities in the tower can alter the inferred reflection coefficients at the tower extremities.

\section{B. Current Derivative Waveforms}

We now discuss the transient behavior of tall towers as deduced from measurements of the time rate of change of current in the tower, that is, the derivative of current with respect to time. It is generally easier to identify the current derivative peak than the current peak during a transient process in the tower because the derivative peak is sharper. When the current derivative with respect to time is measured near the tower top, the arrival of the current wave reflected from the bottom of the tower to the tower top is manifested by a second pronounced current derivative pulse, separated from the first current derivative pulse associated with the incident current wave by the time required for a current wave to make a round-trip along the tower at nearly the speed of light. Of course, this feature is seen only if the incident current risetime is smaller than the current round-trip time. Two examples of such current derivative records and associated current records obtained on the Peissenberg tower are given in Fig. 2. The separation between the negative current derivative peaks in Fig. 2 is $1.15 \mu$ s, which corresponds to twice the time needed for a wave to traverse the 160-m high tower at a speed of $278 \mathrm{~m} \mu \mathrm{s}^{-1}$, slightly less than the speed of light. 


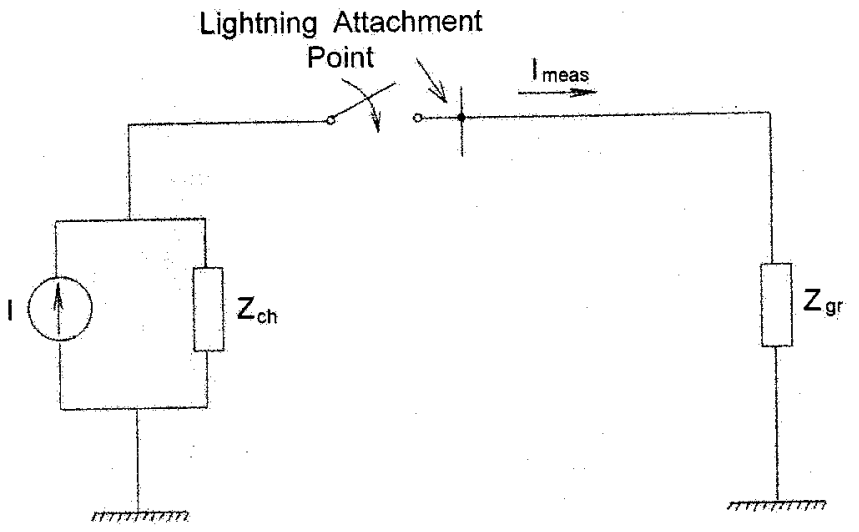

Fig. 3. Equivalent circuit for the case of lightning strike to ground or to an object of negligible height. Lightning is represented by a Norton equivalent circuit composed of an ideal current source representing the short-circuit current $I$ in parallel with a lightning channel equivalent impedance $Z_{\mathrm{cl}_{1}} . Z_{\mathrm{gr}}$ is the effective grounding impedance at the lightning attachment point, and $I_{\text {moas }}$ is the current that would be measured at the attachment point.

Montandon and Beyeler [20] presented, for two lightning events, current derivative waveforms measured at heights of 248 and $175 \mathrm{~m}$ above ground on the 248-m high St. Chrischona tower near Basel, Switzerland. For one of the events the separation between the current derivative pulses was $1.66 \mu \mathrm{s}$ at $248 \mathrm{~m}$ and $1.16 \mu \mathrm{s}$ at $175 \mathrm{~m}$ above ground, consistent with a wave propagation speed nearly equal to the speed of light. For the second event presented by Montandon and Beyeler [20], the current derivative waveforms at both heights appear as singly-peaked pulses.

Shostak et al. [21] presented current derivative waveforms, showing evidence of reflections, measured $474 \mathrm{~m}$ above ground on the 553-m high $\mathrm{CN}$ tower, and associated electric and magnetic field waveforms measured a distance of $2 \mathrm{~km}$ from the tower. They also show current waveforms obtained by integration of the measured current derivative waveforms.

\section{ANALYsis OF EFFeCtS OF THE TRANSIENT PROCESS IN A TAll Strike ObJeCt on MEASUREd CURRENT}

Let us first consider the case of lightning attachment to ground either directly or via an object of negligible height. If we represent lightning by a Norton equivalent circuit, as illustrated in Fig. 3, the lightning current measured at ground, $I_{\text {meas }}=$ $I Z_{\mathrm{ch}} /\left(Z_{\mathrm{ch}}+Z_{\mathrm{gr}}\right)$, where $Z_{\mathrm{ch}}$ is the equivalent impedance of lightning channel, $Z_{\mathrm{gr}}$ is the grounding impedance at the lightning attachment point, and $I$ is lightning current that would be measured at the attachment point if $Z_{\mathrm{gr}}$ were equal to zero (the short-circuit current). The equivalent impedance of lightning channel during the "break-through phase" (part of the lightning attachment process during which the initial current front is formed) is largely determined by the impedance of the "plasma switch" near the attachment point. Once the "plasma switch" is closed, the equivalent impedance is the same as the characteristic impedance of the channel. In the following, we will assume that $Z_{\mathrm{gr}}$ is purely resistive, that is $Z_{\mathrm{gr}}=R_{\mathrm{gr}}$, and that $Z_{\mathrm{ch}}$ is a real number. Further, we will neglect nonlinear processes that may lead to the dependence of $Z_{\mathrm{ch}}$ and $Z_{\mathrm{gr}}$ on lightning current. If lightning were an ideal current source $\left(Z_{\mathrm{ch}}=\infty\right)$, then lightning current measured at ground $I_{\text {meas }}$ would be always equal to the short-circuit current $I$ and, hence independent of $Z_{\mathrm{gr}}$ (as long as it was finite), that is, independent of the conditions at the strike point. As discussed later in this section, for the case of $Z_{\mathrm{ch}}=\infty$ even the presence of a tall ("electrically long") strike object has no effect on the current measured at the lightning attachment point (at the top of the object). In the following, we will refer to the short-circuit current as the "undisturbed" current. It is this current that is used to build a Norton equivalent source for modeling direct lightning strikes to various objects and systems.

In reality, $Z_{\mathrm{ch}}$ ranges from hundreds to thousands of ohms, and measured current is nearly equal to the short-circuit current $\left(I_{\text {meas }} \approx I\right.$ ) when $Z_{\mathrm{gr}} \ll Z_{\mathrm{ch}}$, with the two idealized special cases being $Z_{\mathrm{ch}}=\infty$ (ideal current source) and $Z_{\mathrm{gr}}=0$ (ideal grounding). In practice, the "undisturbed" current would be measured at a well grounded object of negligible height. Rakov et al. [22] showed that triggered-lightning return-stroke currents measured under very different grounding conditions were similar, suggesting that lightning is capable of lowering the grounding impedance encountered at the attachment point to a value that is much lower than $Z_{\mathrm{ch}}$. Such lowering of the grounding impedance is apparently facilitated by developing plasma channels in the ground and along the ground surface.

We now extend the Norton-equivalent circuit shown in Fig. 3 to include a tall strike object represented by a lossless transmission line with characteristic impedance $Z_{0}$. In doing so, we neglect the presence of any upward connecting leader from the strike object. The extended equivalent circuit is shown in Fig. 4(a). Also given in Fig. 4(a) are expressions for the reflection coefficients for current at the top, $\rho_{T}$, and at the bottom, $\rho_{B}$, of the object. Both $\rho_{T}$ and $\rho_{B}$ are assumed to be constants, that is, any nonlinear processes resulting in the dependence of $Z_{\mathrm{ch}}$ or $Z_{\mathrm{gr}}$ on current are neglected. If the switch closes at $t=0$, the first current reflection occurs at the bottom of the object at $t=\tau$, where $\tau$ is the time required for a wave to traverse the length of the object. For $t<\tau$, the downward moving wave "sees" the characteristic impedance of the object $Z_{0}$, and the magnitude of the initial current wave, $I_{0}$, is found from the equivalent circuit shown in Fig. 4(b). Note that the "undisturbed" current is still $I$, as in the case of an object of negligible height, considered above, and that usually $I_{0}<I$. We will now assume (1) that the short-circuit current is a step function of magnitude $I$, (2) that $Z_{\mathrm{gr}}=0$, so that $\rho_{B}=1$, and (3) that $Z_{\mathrm{ch}}=3 Z_{0}$, as found from measurements on both Ostankino and Peissenberg towers (see Section II-A above), so that $\rho_{T}=-0.5$. Under these assumptions, currents versus time at the top, $I_{T}$, and at the bottom, $I_{B}$, of the strike object are as shown in Fig. 5(a) and (b), respectively. In both cases the current magnitude asymptotically approaches the "undisturbed" value $I$ which is indicated by horizontal dashed lines and related to the magnitude $I_{0}$ of the initial current wave propagating down the tower by the equation given in Fig. 4(b). Note that current at the top of the object $I_{T}$ varies from 0.75 to 1.13 of $I$ and that current at the bottom of the object varies from 0.75 to 1.5 of $I$ (from $I_{0}$ to $2 I_{0}$ ). As seen in Fig. 5(a), the "undisturbed" lightning current, $I$, is greater than the injected current, $I_{0}$, but smaller than the maximum value of current $I_{T}$. If lightning could be represented by an ideal current source $\left(Z_{\mathrm{ch}}=\infty\right.$ or $\left.Z_{\mathrm{ch}} \gg Z_{0} ; \rho_{T}=-1\right)$, current at the top of the 


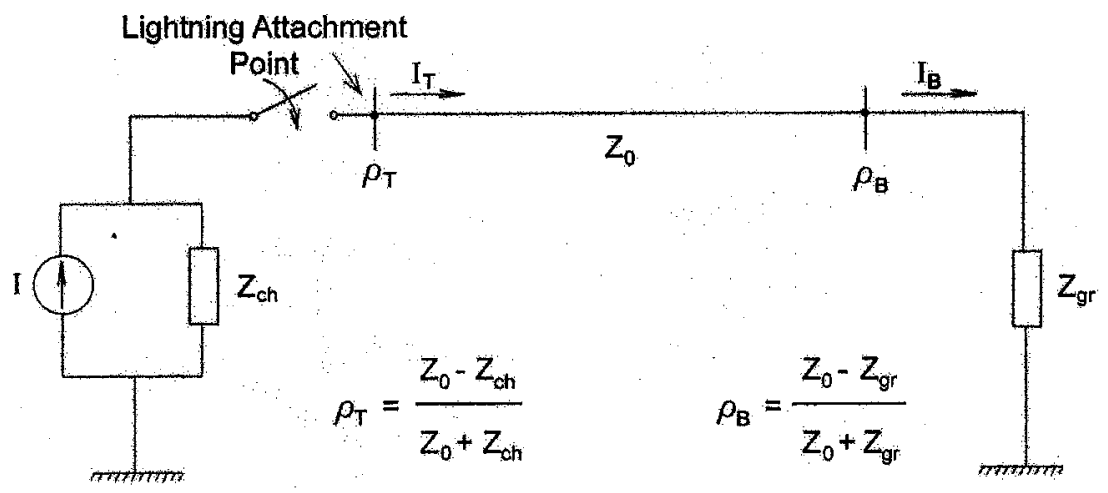

(a)

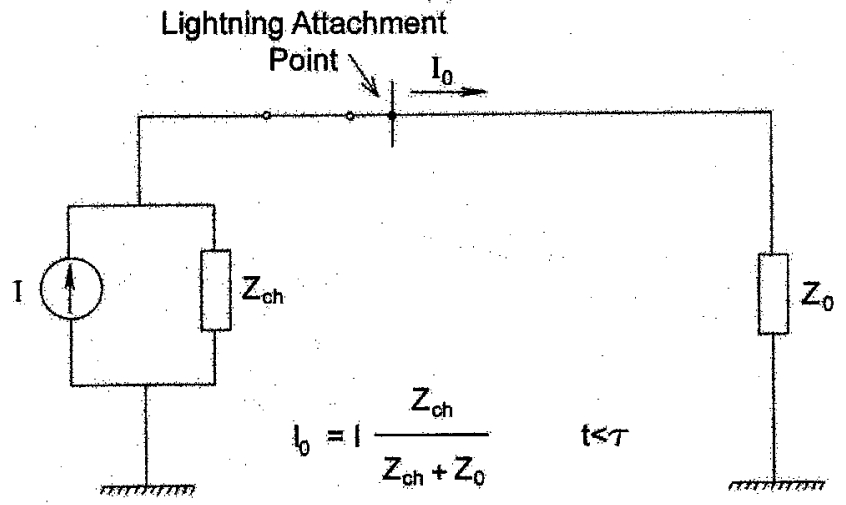

(b)

Fig. 4. (a) Equivalent circuit for the case of lightning strike to a tall grounded object whose characteristic impedance is $Z_{0}$. $Z_{\mathrm{gr}}$ is the effective grounding impedance of the object. $\rho_{T}$ and $\rho_{B}$ are current reflection coefficients at the top and at the bottom of the object, respectively. $I_{T}$ and $I_{B}$ are currents that would be measured at the top and at the bottom of the object, respectively. (b) Equivalent circuit for the case of lightning strike to a tall grounded object for $t<\tau$ where $\tau$ is the time required for a current wave to traverse the length of the object. $I_{0}$ is the magnitude of the initial downward-propagating current wave. See also caption of Fig. 3.
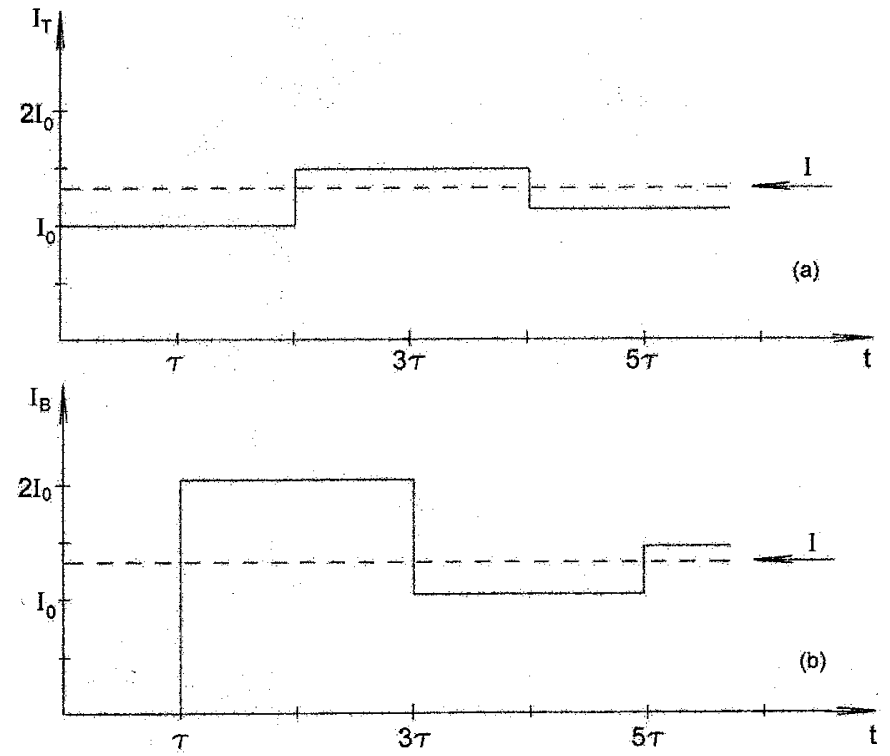

Fig. 5. Current versus time waveforms that would be measured (a) at the top and (b) at the bottom of a tall object if the short-circuit current $I$ were a step function, for the case of $\rho_{B}=1$ and $\rho_{T}=-0.5$ [see Fig. 4(a)]. The "undisturbed" current magnitude, $I$, is indicated by the horizontal dashed lines. The magnitude of the initial downward-propagating current wave, $I_{0}$, is found from the equation given in Fig. 4(b). object $I_{T}$ would be equal to $I$ at all times. Indeed, in this case, (1) current injected into the object would be equal to the source current $\left(I_{0}=I\right)$ and (2) upward-moving current reflections from the bottom of the object would be necessarily cancelled at the object top by downward-moving current reflections from the lightning channel.

We now compare the statistical distributions of return-stroke peak currents measured on objects of different heights and show that these distributions are similar, suggesting that the measured current peaks are not significantly influenced by the presence of the object. The distributions, represented by their $99 \%, 95 \%$, $90 \%, 50 \%, 10 \%$, and $5 \%$ values are summarized in Table I for the following three categories of events: 1) subsequent return strokes in natural downward lightning with the strike object height being equal to $70 \mathrm{~m}$; 2) return-strokes in natural upward (object-initiated) lightning with strike object heights ranging from 70 to $540 \mathrm{~m}$; and 3) return strokes in rocket-triggered lightning with strike object heights ranging from about 5 to $20 \mathrm{~m}$. These three types of return strokes are initiated by downward dart leaders and are expected to have similar characteristics. Return-strokes in categories 2) and 3) are sometimes referred to as subsequent return strokes, by analogy with return strokes in category 1). All data for object-initiated and natural downward lightning were obtained at the top of the strike object except for 
the Ostankino tower for which measurement both at the top and in the lower part of the tower are included in Table I. As seen in Table I, the distributions of peak currents measured at objects with heights ranging from about 5 to $540 \mathrm{~m}$ are not much different from each other. Further, Rakov et al. [22] summarized geometric mean peak currents from six different triggered-lightning experiments in Florida and Alabama. They found a relatively narrow range of currents, 9.9 to $15 \mathrm{kA}$, with no systematic variation with triggering structure height ranging from 4.5 to $20 \mathrm{~m}$ or with lower measurement limit ranging from 1 to $5 \mathrm{kA}$. Thus, the experimental data obtained at objects with heights ranging from 4.5 to $540 \mathrm{~m}$ suggest that current peaks are not significantly affected by the presence of a tall object (as long as measurements are taken at the top of the tall object). This inference is consistent with modeling results of Melander [23] who estimated the influence of the presence of towers on current measurements by Berger et al. [1], Garbagnati and Lo Piparo [24], and Eriksson [25]. In doing so, she represented towers by linear distributed circuits and used a distributed-circuit model of the lightning return stroke with the resistance per unit length being determined by a gas-dynamic model, as proposed by Strawe [26]. Melander [23] found from her modeling that the current measurements of Berger et al. [1] and Garbagnati and Lo Piparo [24] obtained at the top of, respectively, $70-\mathrm{m}$ and $40-\mathrm{m}$ towers are essentially unaffected by the presence of the towers. On the other hand, current peaks measured by Eriksson [25] at the bottom of a 60-m tower were found to be overestimated by a factor of about 1.6.

\section{Electromagnetic Fields Due to Lightning Strikes TO TALL OBJECTS}

Diendorfer and Schulz [27] reported that current peaks estimated by the Austrian lightning locating system tend to be somewhat higher for lightning within a radius of $1 \mathrm{~km}$ of towers located on mountains than for lightning within 1 to $10 \mathrm{~km}$ from the towers. Specifically, for first strokes in 81 negative flashes located within $1 \mathrm{~km}$ of towers, the median peak current was about $12 \mathrm{kA}$, while for 686 negative flashes at distances ranging from 1 to $10 \mathrm{~km}$ from the towers the median peak current was $9.8 \mathrm{kA}$. To explain this difference in median peak currents, Diendorfer and Schulz [27] assumed that, because of lightning locating system errors, most flashes reported by the system as striking ground within $1 \mathrm{~km}$ of towers actually terminated on the towers. A similar effect was noted by Byerley et al. [28] who used U.S. National Lightning Detection Network (NLDN) data to examine lightning strikes to and in the vicinity of tall towers in Oklahoma. Interestingly, Diendorfer and Schulz [27] also observed a considerably larger number of strokes per flash in strikes to towers than in strikes to ground. It is important to note that current peaks reported by lightning locating systems are inferred from electromagnetic field peaks, usually assuming a direct proportionality between the two. Clearly, in the case of using lightning locating system data, it is more appropriate to talk about the difference in electromagnetic field peaks, rather than about the difference in current peaks. Indeed, for the same channel-base current, different field peaks should be expected for different field propagation paths (e.g., Diendorfer et al. 1998a [29]), for different return-stroke speeds, and for different current decay rates along the lightning channel (e.g., Rakov and Dulzon 1987, 1991 [30], [31]; Janischewskyj et al. 1999a [11]). Additionally, the transient behavior of the strike object depends on the current waveshape, and, as a result, different electric or magnetic field signatures can be produced by lightning discharges characterized by the same current peak but different current waveshapes (Rachidi et al. 1998 [9]; Janischewskyj et al. 1998, 1999a [10], [11]). Abdel-Rahman et al. [32] compared two groups of measured current pulses (presumably associated with return strokes) in upward flashes initiated from the $\mathrm{CN}$ tower, the first group including the first pulse in a sequence recorded for each flash, and the second group including all pulses other than the first. They found that the current pulses in the second group were characterized by smaller amplitudes, but tended to produce larger observed magnetic field peaks at a distance of $2 \mathrm{~km}$ from the tower. A lack of proportionality between the $\mathrm{CN}$-tower current peaks and either the electric or magnetic field peaks at a distance of $2 \mathrm{~km}$ from the tower was also reported, from measurements, by Janischewskyj et al. [11] and Shostak et al. [21].

The initial, predominantly radiation electric or magnetic field peak of the lightning return stroke is primarily determined by current flowing near ground. If the lightning short-circuit current (see Section III above) is not influenced by the presence of towers, higher field peaks in the case of lightning strikes to towers might be due to: 1) the existence of two wavefronts propagating simultaneously in opposite directions from the junction point between the descending leader and upward connecting leader from the tower top, with the downward-moving wavefront traversing both the upward-connecting-leader channel and the tower (neglecting current reflection at the tower top); 2) the nearly doubling of the downward-moving current wave on reflection at the bottom of the tower (Section II); and 3) the propagation speed of current waves on the tower being nearly equal to the speed of light, which is higher than the propagation speed of return-stroke current wave in a lightning channel (Idone and Orville 1982 [33]; Wang et al. 1999c [34]). Rachidi et al. [9] noted, from their modeling of lightning strikes to the $\mathrm{CN}$ tower using the modified transmission line model with exponential current decay with height (MTLE model), that the radiation field component of the total field is most affected (enhanced) by the presence of the tower. Perhaps in support of this inference, many electric and magnetic fields measured at a distance of about $200 \mathrm{~m}$ from the 160-m high Peissenberg tower (Zundl 1994a,b [3], [35]), examples of which are given in Fig. 2, exhibit initial peaks, probably due to the radiation field component, that are more pronounced than expected at this distance for strikes to ground. According to Janischewskyj et al. [11], the contribution from the 553-m high $\mathrm{CN}$ tower to the total electric field at a distance of $2 \mathrm{~km}$ from the tower is almost a factor of two greater than the contribution from the lightning channel.

\section{SUMmary}

Current waveforms measured on tall objects may be affected by transient process in the object that involves wave reflections from object extremities and from impedance discontinuities within the object. The equivalent impedance of the lightning channel at the time of the initial current peak is appre- 
ciably higher than the characteristic impedance of an ordinary tall object (a factor of 3 or so for both the Ostankino and Peissenberg towers and about a factor of 2 for the $\mathrm{CN}$ tower). Further, the grounding impedance of a tower is typically lower than its characteristic impedance. As a result, the current reflection coefficient is negative at the top and positive at the bottom of the tower. The similarity of the statistical distributions of subsequent-return-stroke peak currents in: 1) natural downward; 2) natural upward (object-initiated), and 3) rocket-triggered lightning measured at objects with heights ranging from 4.5 to 540 $\mathrm{m}$ suggests that current peaks are not significantly influenced by the presence of a tall object, provided that measurements are taken at the top of the object. This inference is consistent with modeling results of Melander who showed that the current peaks measured in Switzerland and Italy at the top of 70-m and 40-m towers, respectively, are close to the current peaks that would be measured on a well grounded object of neligible height. If lightning current could be represented by an ideal current source, current at the top of the object would be equal to the source current at all times. Indeed, in this case: 1) current injected into the object is equal to the source current; and 2) current reflections from the bottom of the object are cancelled at the object top by current reflections from the lightning channel $\left(\rho_{T}=-1\right)$. The current peak measured at the bottom of a tall object is usually more strongly influenced by the transient process in the object. For example, peak currents measured in the lower part of the 540-m Ostankino tower are about a factor of two higher than the peak currents measured near the tower top, due to the current reflection coefficient at the bottom of the tower being near +1 . A tall metallic strike object replacing the lower part of lightning channel apparently serves to enhance the lightning radiated electromagnetic fields relative to the fields due to similar lightning discharges that attach directly to ground, this effect being more pronounced for the sharper lightning current pulses.

\section{ACKNOWLEDGMENT}

The author would like to thank K. Cummins, F. Heidler, C. A. Nucci, F. Rachidi, T. Shindo, V. Shostak, and M. A. Uman for a number of useful comments.

\section{REFERENCES}

[1] K. Berger, R. B. Anderson, and H. Kroninger, "Parameters of lightning flashes," Electra, vol. 80, pp. 223-237, 1975.

[2] G. Diendorfer and M. A. Uman, "An improved return stroke model with specified channel-base current," J. Geophys. Res., vol. 95, no. 13, pp. 621-644, 1990.

[3] T. Zundl, "Lightning current and LEMP calculations compared to measurements gained at the Peissenberg tower," presented at the 22nd Int. Conf. Lightning Protection, Budapest, Hungary, 1994, Paper R 1c-08.

[4] S. Guerreri, F. Heidler, C. A. Nucci, F. Rachidi, and M. Rubinstein, "Extension of two return stroke models to consider the influence of elevated strike objects on the lightning return stroke current and the radiated electromagnetic field: Comparison with experimental results," in Proc. Int. Symp. on Electromagnetic Compatibility (EMC'96 ROMA), Rome, Italy, 1996, pp. 701-706.

[5] S. Guerrieri, C. A. Nucci, F. Rachidi, and M. Rubinstein, "On the influence of elevated strike objects on directly measured and indirectly estimated lightning currents," IEEE Trans. Power Delivery, vol. 13, pp. 1543-1555, Oct. 1998.

[6] S. Guerrieri, E. P. Krider, and C. A. Nucci, "Effects of traveling-waves of current on the initial response of a tall Franklin rod," in Proc. 25th Int. Conf. Lightning Protection, Rhodes, Greece, 2000, pp. 94-99.
[7] R. Rusan, W. Janischewskyj, A. M. Hussein, and J.-S. Chang, "Comparison of measured and computed electromagnetic fields radiated from lightning strikes to the Toronto CN tower," in Proc. 23rd Int. Conf. on Lightning Protection, Florence, Italy, 1996, pp. 297-303.

[8] H. Motoyama, W. Janischewskyj, A. M. Hussein, R. Rusan, W. A. Chisholm, and J.-S. Chang, "Electromagnetic field radiation model for lightning strokes to tall structures," IEEE Trans. Power Delivery, vol. 11, pp. 1624-1632, July 1996.

[9] F. Rachidi, W. Janischewskyj, A. M. Hussein, C. A. Nucci, S. Guerrieri, and J. S. Chang, "Electromagnetic fields radiated by lightning return strokes to high towers," in Proc. 24th Int. Conf. on Lightning Protection, Birmingham, U. K., 1998, pp. 23-28.

[10] W. Janischewskyj, V. Shostak, and A. M. Hussein, "Comparison of lightning electromagnetic field characteristics of first and subsequent return strokes to a tall tower: 1 Magnetic field," in Proc. 24th Int. Conf. on Lightning Protection, Birmingham, U. K., 1998, pp. $245-251$.

[11] —, "Lightning electric field characteristics of first and subsequent return strokes to a tall tower," in Proc. 11th Int. Symp. on High Voltage Engineering, vol. 1, IEE Publ. no. 467, London, U. K., 1999a, pp. 270-274.

[12] V. Shostak, W. Janischewskyj, A. M. Hussein, J.-S. Chang, and B. Kordi, "Return-stroke current modeling of lightning striking a tall tower accounting for reflections within the growing channel and for upward-connecting discharges," in Proc. 11 th Int. Conf. on Atmospheric Electricity, Guntersville, AL, 1999a, pp. 123-126.

[13] V. Shostak, W. Janischewskyj, A. M. Hussein, and B. Kordi, "Electromagnetic fields of lightning strikes to a tall tower: A model that accounts for upward-connecting discharges," in Proc. 25th Int. Conf. Lightning Protection, Rhodes, Greece, 2000, pp. 60-65.

[14] H. Goshima, H. Motoyama, A. Asakawa, A. Wada, T. Shindo, and S. Yokoyama, "Characteristics of electromagnetic fields due to winter lightning stroke current to a high stack," Trans. Inst. Electr. Eng. Jpn., vol. 120-B, no. 1, pp. 44-48, 2000.

[15] V. A. Rakov and M. A. Uman, "Review and evaluation of lightning return stroke models including some aspects of their application," IEEE Trans. Electromagn. Compat., vol. 40, pp. 403-426, Nov. 1998.

[16] B. N. Gorin and A. V. Shkilev, "Measurements of lightning currents at the Ostankino tower," Elektrich., no. 8, pp. 64-65, 1984. in Russian.

[17] B. N. Gorin, V. I. Levitov, and A. V. Shkilev, "Lightning strikes to the Ostankino tower," Elektrich., no. 8, pp. 19-23, 1977. (in Russian).

[18] O. Beierl, "Front shape parameters of negative subsequent strokes measured at the Peissenberg tower," in Proc. 21st Int. Conf. on Lightning Protection, Berlin, Germany, 1992, pp. 19-24.

[19] W. Janischewskyj, V. Shostak, J. Barratt, A. M. Hussein, R. Rusan, and J.-S. Chang, "Collection and use of lightning return stroke parameters taking into account characteristics of the struck object," in Proc. 23rd Int. Conf. on Lightning Protection, Florence, Italy, 1996, pp. 16-23.

[20] E. Montandon and B. Beyeler, "The lightning measuring equipment on the Swiss PTT telecommunications tower at St. Chrischona, Switzerland," presented at the 22nd Int. Conf. Lightning Protection, Budapest, Hungary, 1994, Paper R 1c-06.

[21] V. Shostak, W. Janischewskyj, A. M. Hussein, and B. Kordi, "Characteristics of return stroke current and electromagnetic field waveforms observed in multistroke lightning flashes to a tall tower," in Proc. 11th Int. Symp. on High Voltage Engineering, vol. 2, IEE Publ. no. 467, London, U.K., 1999b, pp. 389-392.

[22] V. A. Rakov, M. A. Uman, K. J. Rambo, M. I. Fernandez, R. J. Fisher, G. H. Schnetzer, R. Thottappillil, A. Eybert-Berard, J. P. Berlandis, P. Lalande, A. Bonamy, P. Laroche, and A. Bondiou-Clergerie, "New insights into lightning processes gained from triggered-lightning experiments in Florida and Alabama," J. Geophys. Res., vol. 103, no. 14, pp. 117-130, 1998.

[23] B. G. Melander, "Effects of tower characteristics on lightning arc measurements," in Proc. 1984 Int. Conf. on Lightning and Static Electricity, Orlando, FL, 1984, pp. 34/1-34/12.

[24] E. Garbagnati and G. B. Lo Piparo, Parameter von Blitzstroemen, ETZ-A 103, pp. 61-65, 1982.

[25] A. J. Eriksson, "Lightning and tall structures," Trans. South African Inst. Electr. Eng., vol. 69, pp. 238-252, Aug. 1978.

[26] D. F. Strawe, "Non-linear modeling of lightning return strokes," in Proc. Federal Aviation Administration/Florida Institute of Technology Workshop on Grounding and Lightning Technology, Melbourne, FL, 1979, pp. $9-15$. 
[27] G. Diendorfer and W. Schulz, "Lightning incidence to elevated objects on mountains," in Proc. 24th Int. Conf. on Lightning Protection, Birmingham, U. K., 1998, pp. 173-175.

[28] L. G. Byerley, W. A. Brooks, R. C. Noggle, and K. L. Cummins, "Towers, lightning and human affairs," in Proc. 11th Int. Conf. Atmospheric Electricity, Guntersville, AL, 1999, pp. 180-183.

[29] G. Diendorfer, W. Schulz, and F. Fuchs, "Comparison of correlated data from the Austrian lightning location system and measured lightning currents at the Peissenberg tower," in Proc. 24th Int. Conf. on Lightning Protection, Birmingham, U. K., 1998a, pp. 168-172.

[30] V. A. Rakov and A. A. Dulzon, "Calculated electromagnetic fields of lightning return stroke," Tekh. Elektrod., no. 1, pp. 87-89, 1987.

[31] _ "A modified transmission line model for lightning return stroke field calculations," in Proc. 9th Int. Zurich. Symp. on Electromagnetic Compatibility, Zurich, Switzerland, 1991, pp. 229-235.

[32] M. Abdel-Rahman, W. Janischewskyj, A. M. Hussein, F. Rachidi, and J. S. Chang, "Statistical analysis of magnetic fields due to $\mathrm{CN}$ tower multistroke flashes," in Proc. 24th Int. Conf. on Lightning Protection, Birmingham, U. K., 1998, pp. 107-112.

[33] V. P. Idone and R. E. Orville, "Lightning return stroke velocities in the Thunderstorm Research International Program (TRIP)," J. Geophys. Res., vol. 87, no. C6, pp. 4903-4915, 1982.

[34] D. Wang, N. Takagi, T. Watanabe, V. A. Rakov, and M. A. Uman, "Observed leader and return-stroke propagation characteristics in the bottom $400 \mathrm{~m}$ of the rocket triggered lightning channel," J. Geophys. Res., vol. 104 , no. 14 , pp. 369-376, 1999c.

[35] T. Zundl, "First results of the coordinated lightning current and LEMP measurements at the Peissenberg tower," presented at the 22nd Int. Conf. Lightning Protection, Budapest, Hungary, 1994, Paper R 1c-09.

[36] R. B. Anderson and A. J. Eriksson, "Lightning parameters for engineering application," Electra, vol. 69, pp. 65-102, 1980.

[37] F. Fuchs, E. U. Landers, R. Schmid, and J. Wiesinger, "Lightning current and magnetic field parameters caused by lightning strikes to tal structures relating to interference of electronic systems," IEEE Trans. Electromagn. Compat, vol. 40, pp. 444-451, Nov. 1998.

[38] K. Berger, "Blitzstrom-Parameter von Aufwartsblitzen," Bull. Schweiz Elektrotech, no. 69, pp. 353-360, 1978.

[39] J. H. Hagenguth and J. G. Anderson, "Lightning to the Empire State Building-Part III," AIEE Trans., pt. III, vol. 71, pp. 641-649, Aug. 1952.

[40] R. J. Fisher, G. H. Schnetzer, R. Thottappillil, V. A. Rakov, M. A. Uman, and J. D. Goldberg, "Parameters of triggered-lightning flashes in Florida and Alabama," J. Geophys. Res., vol. 98, no. 22, pp. 887-902, 1993.

[41] P. Depasse, "Statistics on artificially triggered lightning," J. Geophys. Res., vol. 99, no. 18, pp. 515-522, 1994.
[42] Y. Baba and M. Ishii, "Numerical electromagnetic field analysis of lightning current in tall structures," IEEE Trans. Power Delivery, vol. 16, pp. 324-328, 2001.

[43] F. Fuchs, "On the transient behavior of the telecommunication tower a the mountain Hoher Peissenberg," in Proc. 24th Int. Conf. on Lightning Protection, vol. 1, Birmingham, U. K., 1998, pp. 36-41.

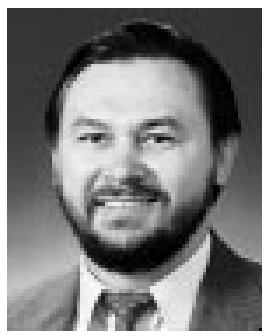

Vladimir A. Rakov received the Master's and Ph.D. degrees, both from the Tomsk Polytechnical University (Tomsk Polytechnic), Tomsk, Russia in 1977 and 1983, respectively.

From 1977 to 1979, he was an Assistant Professor of Electrical Engineering at Tomsk Polytechnic. In 1978, he became involved in lightning research at the High Voltage Research Institute, a division of Tomsk Polytechnic, where from 1984 to 1994 , he held the position of Director of the Lightning Research Laboratory. In 1985, Dr. Rakov received the rank of Senior Scientist in High Voltage Engineering. In 1998, Dr. Rakov was Guest Professo at the Technical University of Vienna, Vienna, Austria, and in 2001 at the Swiss Federal Institute of Technology, Lausanne, Switzerland. In 1991, he joined the faculty of the Department of Electrical and Computer Engineering at the University of Florida, Gainesville, where he is currently Professor with. He is the author or co-author of over 30 patents and over 200 papers and technical reports on various aspects of lightning, with 75 papers being published in reviewed journals.

Dr. Rakov has been named an Inventor of the USSR (1986) and received a Silver Medal from the (USSR) National Exhibition of Technological Achievements (1987). He is a member of the American Geophysical Union (AGU), the American Meteorological Society (AMS), the Society of Automotive Engineers (SAE), and a Senior Member of IEEE. He is also a member of the CIGRE Working Group 33.01 "Lightning," the IEEE Working Group on the Lightning Performance of Distribution Lines, the International Commission on Atmospheric Electricity, the Steering Committee for the International Symposium on Lightning Protection (SIPDA), the AMS Science and Technology Committee on Atmospheric Electricity, the Scientific Committee of the International Conference on Lightning Protection (ICLP), and the UL Standards Technical Panel for Lightning Protection Components. He is Chairman of the Technical Committee on Lightning of the biennial International Zurich Symposium on Electromagnetic Compatibility and of the AGU Committee on Atmospheric and Space Electricity (CASE). 